\title{
Los procesos de regionalización en España y Francia (una nota de lectura de la tesis de R. Pasquier)
}

\section{J. Vilas Nogueira *}

En su tesis doctoral, Romain PASQuier ${ }^{1}$ se ha propuesto la elaboración de un marco interpretativo («une grille de lecture sociologique», en sus palabras) de la diversidad del potencial movilizador de las regiones a escala europea. Al efecto compara los procesos de regionalización que han tenido lugar durante, aproximadamente, los últimos treinta años en España y Francia, más concretamente en Galicia y La Rioja, por una parte, y Bretaña y región Centro, por otra. De este modo, la investigación abre la posibilidad simultánea de una comparación internacional (España y Francia), una comparación intranacional (Galicia y La Rioja, por un lado; Bretaña y la región Centro, por otro), y una comparación internacional-interregional (Bretaña y Galicia; la región Centro y La Rioja). El autor trata de contribuir a la comprensión de las dinámicas de recomposición territorial de los intereses y de la acción pública como consecuencia de las interacciones entre la europeización de los procesos políticos y las dinámicas de regionalización. Sin embargo, el limitado número de casos estudiado, y sobre todo su reducción a casos españoles y franceses, arroja dudas sobre la justificación de un objetivo tan ambicioso como la elaboración de un marco interpretativo tan general.

La estrategia de la investigación desarrollada por PASQUIER para aplicar su marco interpretativo comparte la dimensión diacrónica y la sincrónica. Una característica de su investigación, que el autor enfatiza particularmente, es la referencia a la temporalidad de los espacios y de las redes que definen modelos regionales de acción colectiva, diferenciados según las regiones consideradas. Temporalidad que es contemplada sobre un período relativamente dilatado, desde el fin del siglo XIX hasta nuestros días.

El trabajo se inscribe en una línea tendente a la renovación de los enfoques de estos fenómenos. Más concretamente, PAS. QUIER se sirve del concepto de «capacidad política», entendida como un proceso por el que los actores políticos y sociales producen visiones del mundo que estructuran relaciones de cooperación y acuerdos informales en la definición de uno o varios «intereses». Partiendo de este concepto, el autor hace un modelo de análisis con cuatro entradas: los modelos regionales de acción colectiva, las reglas constitutivas de los sistemas políticos, la constitución de coaliciones de intereses regionales y la producción de políticas públicas regionales. Pretende, así, obtener una explicación de la capacidad diferencial de los órdenes institucionales para los objetivos de la regionalización. Yo creo que el trabajo se hubiese beneficiado del establecimiento explicito y más enfático de una tipología de los procesos de regionalización, que debería integrar, por lo menos, tres categorías: 1) aquellos casos en los que los procesos de regionalización (o de «construcción nacional») son una mera coartada para la persecución de la independencia estatal. Aunque, a veces no se repare en ello, en algunos de estos procesos la invocación ad nauseam de la «construcción nacional» es mera superchería. Lo único que se quiere es dotar de un Estado independiente a una comunidad «construida» hace mucho tiempo, con frecuencia desde la prehistoria, en base a una comunidad lingüistica, a veces prerromana, o una comunidad de factor sanguíneo rh $\mathrm{u}$ otras particularidades anatómicas, craneales o inguinales 
(por cierto llamar a estas comunidades, reales o ilusorias, «naciones» se opone frontalmente a las acepciones adquiridas por el término desde la Edad Moderna). Es el caso de los procesos impulsados por el nacionalismo vasco radical. Respecto de estos casos el marco interpretativo elaborado por PASQUIER sólo sirve para confirmar la constitutiva irracionalidad que preside estos procesos y para establecer su radical heterogeneidad, a pesar de las apariencias, con las otras categorías; 2) aquellos casos en los que los procesos de regionalización [como suele ser la norma en los desarrollados en Galicia (y quizá también en Bretaña)] persiguen reinvindicar una institucionalización política diferenciada, al servicio de una identidad colectiva histórica, ya sea tematizada en términos de identidad regional, ya «nacional», pero no necesariamente excluyente del ámbito del Estado nacional establecido. En la realidad empírica, al primar la sustantivización historicista de los procesos, los objetivos de promoción de los «intereses regionales» o de desarrollo económico suelen funcionar más como instrumento legitimador del a priori de la «identidad histórica» que como objetivos sustanciales; 3) finalmente, aquellos casos en que procesos de regionalización emprendidos a nivel nacional-estatal (o mímesis de procesos de regionalización del tipo 2) suponen una estructura de oportunidad para elites económicas y/o políticas locales promotoras de «intereses regionales» (como es el caso de La Rioja $y$, en gran parte fallido según PASQuier, de la región Centro francesa). En este tipo, la situación es inversa al caso anterior. Lo sustancial es la promoción de los «intereses» y el instrumento legitimador la «fabricación» de una identidad regional.

Naturalmente, se trata de «tipos ideales». Empíricamente pueden no manifestarse con entera nítidez. Las dos últimas categorías abren la posibilidad de reconfiguración de los Estados nacionales desde el convencional paradigma vertical o de centralidad a uno de Estado-red, en el que no hay la escisión centro/periferias, sino la articulación conectiva de diversos nodos. No habría ya un único centro de concentración del poder, que pudiera disponer de «todos» los recursos necesarios para la regulación de los problemas colectivos. Se plantea, entonces, la cuestión de la recomposición de las lógicas de acción pública y de la recomposición de los «intereses» legitimados territorialmente y de las identidades colectivas de base territorial. Para muchos investigadores esta red conectiva de escenarios y de actores daría una nueva legitimidad a las pretensiones de identidad política infranacional. Pero esto sólo será verdad si, a su vez, estas pretensiones abandonan la lógica, a escala inferior, del Estado nacional de los siglos XVII y XIX.

Respecto a la influencia de las reglas de constitución y dinámica de los sistemas políticos nacionales respectivos en los procesos de regionalización, aunque PASQUIER abunda por extenso y competentemente en esta cuestión, no estoy seguro de que siempre extraiga las oportunas inferencias. Ciertamente, desde los años setenta asistimos a un proceso de crecimiento, en toda
Europa occidental, del porcentaje de gasto público correspondiente a las comunidades locales y regionales. Sin embargo, la capacidad financiera de las instituciones regionales es muy diversa en España y Francia. En este último país el peso financiero de las regiones, aunque haya crecido relativamente mucho en los últimos años, es muy modesto. En España, en cambio, supera actualmente el $25 \%$. Por ejemplo, el presupuesto de la Comunidad Autónoma de Galicia es más de doce veces superior al de la región de Bretaña, para una población equivalente y un PIB inferior. Por otro lado, mientras que los recursos financieros de las regiones francesas apenas suponen el $10 \%$ de los de las comunas y departamentos, en España el gasto regional es muy superior al de las entidades locales. Estas enormes diferencias indican que mientras las Comunidades Autónomas españolas son fundamentalmente administraciones prestadoras de servicios, entre ellos algunos tan costosos como la salud y la educación públicas, las administraciones regionales francesas son sustancialmente administraciones de «misión» centradas en aspectos de desarrollo económico, ordenación del territorio, medio ambiente, asuntos europeos y prospectiva.

Aquella diferencia se manifiesta también en los efectivos humanos de las Administraciones regionales en uno y otro país. Según datos de Bouzas ${ }^{2}$, la Comunidad Autónoma de Galicia empleaba a finales de 1997 la enorme cifra de más de 67.000 personas [cerca de 14.000 empleados de Administrración general, incluidos funcionarios de de carrera, interinos y contratados, más el personal de los servicios de Salud y Educación públicas (excluidas las Universidades), algo más de 25.000 y 28.000 empleados, respectivamente]. En la misma fecha, en cambio, el personal administrativo de la región de Bretaña no llegaba a las 300 personas (PASQuiER: 195).

Estos desarrollos suscitan una cuestión quizá embarazosa para la construcción de PASQUIER. ¿En qué medida es pertinente una «lectura» única de procesos de regionalización como los franceses, que han abocado a entidades especializadas en funciones de promoción y desarrollo económico, que las hacen complementarias de la Administración estatal y comunal, y los procesos de regionalización españoles, que han dado por resultado Administraciones prestacionales generales, en permanente rivalidad con la Administración estatal y la local?

La cuestión resurge, a propósito del cuadro de relaciones entre los diferentes niveles de Administración. Atinadamente, PASQUIER observa que en Francia los «contratos-plan» Estado-Regiones imponen límites a la capacidad de negociación de las regiones, pero permiten participar a todas ellas, de modo sustancialmente homogéneo, con peso importante en el proceso. En cambio, en España aunque el modelo de negociación Estado-Comunidades Autónomas deja más posibilidades de acción a los gobiernos regionales consagra una fuerte asimetría en la capacidad de las regiones de pesar sobre la Administración central. En último término, esta diferencia, eno será reflejo del 
contraste entre Administraciones «naturalmente» inducidas a la cooperación, como es el caso en Francia, dado el carácter especializado de las regiones, y Administraciones «naturalmente» inducidas a la concurrencia, como es el caso de España, dada la homogeneidad sustancial de nuestras Comunidades con el Estado? Por eso, el caso francés, creo yo, induce a PASQUIER a una sobrevaloración y a una mala comprensión del puesto de Delegado del Gobierno y, más en general, de la Administración periférica del Estado. En nuestro modelo (que no es muy «modélico» en este aspecto) la Administración periférica del Estado es, en muchos ramos, una supervivencia anacrónica; y el Delegado, lo es del Gobierno, no del Estado. Su papel sólo es relevante en las cuestiones de orden público. Nunca es interlocutor relevante del Gobierno regional en las cuestiones de Administración general.

PASQUIER estudia la historia de la vida política y de la acción colectiva de cada una de las regiones a fin de descubrir la «memoria colectiva» y los modelos de intervención ligados a la construcción regional. Apoyándose en la bibliografía existente, en un gran número de entrevistas y, en ciertos casos, de datos de archivo, el autor ha intentado reconstituir la manera cómo el trabajo político de los actores regionales ha conseguido movilizar (o ha fracasado en ello) los recursos regionales para profundizar la identidad regional y cómo, en una especie de feedback, estos actores regionales se han beneficiado de la identidad regional como un elemento de potenciación de sus recursos, para actuar en un espacio de acción pública «multinivel» europeo, en lugar de insistir en temas más «clásicos» en la comparación interregional (como los aparatos institucionales, las competencias, etc.). A este propósito, mi principal reserva se centra en la ausencia de «problematización» por parte del autor del concepto de «intereses regionales». Esto le conduce a implicar que los actores regionales persiguen siempre «intereses» regionales y que los persiguen «mejor» que actores no regionales. Pero, dista de ser evidente que, en primer lugar, los intereses pretendidamente «regionales» sean siempre tales. Además de que esta pretensión pueda ser (y sea, con frecuencia) un mero artificio legitimador de intereses mucho más particulares, suele conducir a fórmulas muy conservadoras. En general, las elites económicas y políticas suelen ser más bien vesperales (por «flirtear» con Hegel) y suelen entender que los sectores más tradicionales son los más representativos de los «verdaderos» intereses regionales (o nacionales, si se cambia de nivel). Con mucha frecuencia esto conduce a la adopción de políticas de protección de sectores en crisis estructural, obstaculizando paradójicamente, el desarrollo regional. Para las elites económicas la motivación puede ser la mera pereza mental y la defensa de intereses y posiciones adquiridos. Para las elites políticas hay, además, obvios incentivos legitimadores para abrazar polí ticas como éstas, que pueden ser en realidad retardatarias. En segundo lugar, está la cuestión de si los «intereses regionales» se benefician del impulso de la «capacidad regional», problema que obviamente no admite una sola respuesta, pues depende de varios factores, pero sobre todo de qué se esconda bajo el término de «intereses regionales». Ciertamente, la suposición de que los actores regionales son los mejores defensores de los «intereses regionales» está en la base de la legitimación de los regionalismos y «nacionalismos» centrífugos, pero dista de ser evidente y de ser tomada acríticamente puede ser proyectada a nivel de comunidades inferiores, abocando a un absurdo reduccionismo anarcoide.

La obra de PASQUIER deja traslucir un sólido trabajo de investigación empírica. En concreto, su tratamiento de las regiones españolas muestra un conocimiento muy profundo, no fácil de encontrar en un estudioso extranjero. Aunque cometa algunos errores, no son graves y sobre todo no suelen afectar a su argumentación. Respecto de Galicia, la objeción más grave que se le podría hacer es que, con frecuencia, incluye bajo la rúbrica de «nacionalismo» posiciones regionalistas, autonomistas, galleguistas y las propiamente nacionalistas. En su descargo, cabe aducir que la propia bibliografía generada en Galicia sobre estas cuestiones no es siempre clara. Hace ya tiempo propuse ${ }^{3}$ retener la palabra «diferencialismo» para expresar el residuo común a estos diversos movimientos e ideologías, sin embargo, tan diferentes, e incluso opuestos, entre ellos. Mi propuesta no ha tenido éxito. También PASQUIER aunque cita este trabajo mío ignora sus desarrollos, lo que le conduce a afirmaciones manifiestamente inconsistentes como la calificación de la ORGA como partido nacionalista, y sobre todo, lo que es más grave, a una mala comprensión del proceso autonomista que aboca al presente Estatuto. En contra de lo que escribe el autor, los nacionalistas gallegos no tuvieron ninguna incidencia en este proceso, embarcados como estaban en una huida hacia delante, en prosecución de la autodeterminación (objetivo no sólo «gaseoso», sino estridentemente prematuro). Tampoco los galleguistas, salvo el prudente y sagaz Ramón PiNEIRO, incidieron demasiado en este proceso (más allá de PASQUIER y de su obra, es bueno recordar que una parte importante de los beneficiarios de este proceso no sólo no lo propiciaron, sino que lo dificultaron cuanto pudieron).

En suma, pese a las reservas expresadas, la tesis de Romain PASQuirr me parece excelente, tanto en la vertiente teórico-constructiva, como en la de análisis histórico-empírico de las regiones que estudia. 
* Universidad de Santiago de Compostela.

' Romain PASQUER, La capacité politique des régions. Une comparaison France-Espagne, Tesis de Doctorado en Ciencia Política, Université de Rennes, octubre 2000.

2 Ramón A. Bouzas, Análisis organizativo de la Administración de una Comunidad Autónoma: Xunta de Galicia 1982-1997 (Tesis de Doctorado), Universidad de
Santiago de Compostela, Departamento de Sociología y Ciencia Política y de la Administración, 1999.

3 J. VaAs NOGuerRA, «Ideología y periodización del diferencialismo gallego en el siglo XIX», en VII Coloquio de Pau, De la crisis del Antiguo Régimen al franquismo. Ideologia y sociedad en la España contemporánea, vol. 2, Madrid: Cuadernos para el Diálogo, 1977. 